\title{
Suitability of existing Software development Life Cycle (SDLC) in context of Mobile Application Development Life Cycle (MADLC)
}

\author{
Anureet Kaur \\ Ph.D. Research Scholar \\ Punjab Technical University, \\ Kapurthala, Punjab
}

\author{
Kulwant Kaur, Ph.D \\ Dean \&Asst.Professor \\ School of IT, Apeejay Institute of \\ Management Technical Campus Jalandhar, Punjab
}

\begin{abstract}
Mobile technology has seen a steep rise in its demand and usage, which has further increased the need for specialized software for mobile devices. For developing mobile applications, existing software development process models are incorporated. But looking at the remarkable growth of mobile devices, the complexity involved in development of mobile applications needs a dedicated life cycle process model, instead of using traditional life cycle process models. Although many existing life cycle models are adapted for mobile apps development but there are certain constraints that needs to be addressed specifically, such as Performance Factor, Power Factor, Band Factor, Connectivity Factor, Context Factor, Graphic Interface Factor, Input Interface Factor, etc. It is a stimulating task to develop mobile application due to these technical constraints. In this paper, a comparative analysis of traditional software life cycle models that are widely used in software development and also discussed the strengths and weakness of using these models for mobile application development. It also emphasize on need for dedicated mobile application development life cycle process in order to provide high quality mobile apps and minimize mobile app development problems and errors that are faced at later stage.
\end{abstract}

\section{Keywords}

Software Engineering, Mobile Applications, Application Development, Software Development Life Cycle

\section{INTRODUCTION}

In recent years, due to portability and ease of use, maximum population has shifted to mobile devices. This remarkable growth of mobile devices has taken over desktop computers and is becoming a very important part of our life. The applications developed for mobile devices are becoming more and more advanced and complex, adjusting to the constantly improving computational power of hardware. International Data Corporation (IDC) hosted a web conference "IDC FutureScape: Worldwide Mobile Enterprise Applications and Solutions 2015 Predictions" on Dec 18, 2014 .According to IDC by $2017,87 \%$ of the worldwide smart connected device market will be tablets and smartphones, with PCs (both desktop and laptop) making up only $13 \%$ of the market. IDC also estimates that tablet sales will surpass PCs on an annual basis by 2015. [1,2]

According to mobile analytics firm Flurry, mobile app usage grew faster year-over-year. Messaging and social apps showed great increase in year 2013 and 2014 but 2015 proves as lucrative for ecommerce startups. Figure1 shows the growth of usage in mobile apps from 2013 to 2014. [3] The trend for mobile application development has spread so vastly that today everyone is using applications for everything from health to sports, from education to games; every imaginable domain in layman's life is making use of mobile apps. Smart devices have reached everyone's hands; yesterday it seemed like a luxury, today it is a necessity. The mobile internet usage has brought forward the trend of connectivity on-the-go. The applications are becoming more useful because the user gets to use them anywhere and everywhere [4].

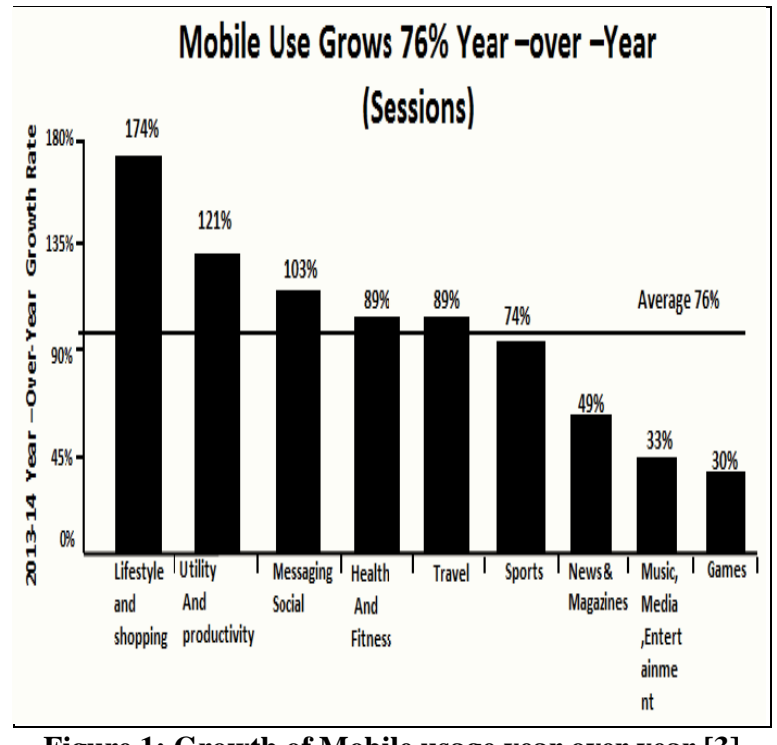

Figure 1: Growth of Mobile usage year over year [3]

The objective of this paper is to answer fundamental questions about mobile app development for new and experienced application developers alike.

\section{LITERATURE OF THE CURRENT SOFTWARE DEVELOPMENT PROCESS MODELS}

A Software development lifecycle is abstract representation of various processes used in the development of any software. There exist different lifecycle models. Some of them areWaterfall model, spiral model, agile model and prototyping model. Although there is not much difference between developing applications for desktops, Web or for mobile devices, the basic steps are always the same: requirements gathering, designing, implementing, testing, and delivery; but the details are different. So it is not possible to simply transfer the models of traditional software development to mobile application development without making significant amendments. A summarized comparison tableof various process models used in software engineering is shown in Table 1 


\begin{tabular}{|c|c|c|c|c|c|c|c|c|}
\hline $\begin{array}{c}\text { Parameter } \\
\downarrow\end{array}$ & $\begin{array}{l}\text { Process } \\
\text { Model } \\
\rightarrow\end{array}$ & $\begin{array}{l}\text { Waterfall } \\
\text { Model }\end{array}$ & $\begin{array}{l}\text { Incremental } \\
\text { Model }\end{array}$ & $\begin{array}{l}\text { Prototype } \\
\text { Model }\end{array}$ & $\begin{array}{l}\text { RAD } \\
\text { Model }\end{array}$ & $\begin{array}{l}\text { Spiral } \\
\text { Model }\end{array}$ & $\begin{array}{l}\text { Agile } \\
\text { Model }\end{array}$ & $\begin{array}{l}\text { Xp } \\
\text { programming }\end{array}$ \\
\hline \multicolumn{2}{|c|}{$\begin{array}{l}\text { Clear Requirement } \\
\text { Specifications }\end{array}$} & Initial level & Initial level & $\begin{array}{l}\text { At } \\
\text { medium } \\
\text { level }\end{array}$ & $\begin{array}{l}\text { Initial } \\
\text { level }\end{array}$ & $\begin{array}{l}\text { Initial } \\
\text { level }\end{array}$ & $\begin{array}{l}\text { Change } \\
\text { imcrementally }\end{array}$ & Initial level \\
\hline \multicolumn{2}{|c|}{ Feedback from user } & No & No & Yes & No & No & No & Yes \\
\hline \multicolumn{2}{|c|}{ Speed to change } & Low & High & Medium & No & High & High & High \\
\hline \multicolumn{2}{|c|}{ Predictability } & Low & Low & High & Low & Medium & High & High \\
\hline \multicolumn{2}{|c|}{ Risk identification } & $\begin{array}{l}\text { At initial } \\
\text { level }\end{array}$ & No & No & No & Yes & Yes & Yes \\
\hline \multicolumn{2}{|c|}{$\begin{array}{l}\text { Practically } \\
\text { implementation }\end{array}$} & No & Low & Medium & No & Medium & High & High \\
\hline \multicolumn{2}{|l|}{ Loom } & $\begin{array}{l}\text { Systematic } \\
\text { sequence }\end{array}$ & $\begin{array}{l}\text { Iterative } \\
\text { sequence }\end{array}$ & $\begin{array}{l}\text { Priority } \\
\text { on } \\
\text { customer } \\
\text { feedback }\end{array}$ & $\begin{array}{l}\text { Use } \\
\text { readym } \\
\text { ade } \\
\text { compon } \\
\text { ent }\end{array}$ & $\begin{array}{l}\text { Identificat } \\
\text { ion of risk } \\
\text { at each } \\
\text { stage }\end{array}$ & $\begin{array}{l}\text { Highly customer } \\
\text { satisfaction and } \\
\text { incremental } \\
\text { development. }\end{array}$ & $\begin{array}{l}\text { Customer } \\
\text { satisfaction and } \\
\text { incremental } \\
\text { development }\end{array}$ \\
\hline \multicolumn{2}{|c|}{ Any variation done } & $\begin{array}{l}\text { Yes-v } \\
\text { model }\end{array}$ & No & No & No & $\begin{array}{l}\text { Yes-win } \\
\text { win spiral }\end{array}$ & No & No \\
\hline \multicolumn{2}{|c|}{ Understandability } & Simple & Intermediate & $\begin{array}{l}\text { Intermedi } \\
\text { ate }\end{array}$ & $\begin{array}{l}\text { Interme } \\
\text { diate }\end{array}$ & Hard & Much complex & Intermediate \\
\hline \multicolumn{2}{|l|}{ Precondition } & $\begin{array}{l}\text { Requireme } \\
\text { nt clearly } \\
\text { defined }\end{array}$ & $\begin{array}{l}\text { Core product } \\
\text { should } \\
\text { clearly } \\
\text { defime }\end{array}$ & $\begin{array}{l}\text { Clear idea } \\
\text { of Quick } \\
\text { Design }\end{array}$ & $\begin{array}{l}\text { Clean } \\
\text { idea of } \\
\text { Reuse } \\
\text { compon } \\
\text { ent }\end{array}$ & No & No & No \\
\hline \multicolumn{2}{|c|}{ Industry approach } & Basic & Basic & Medium & $\begin{array}{l}\text { Mediu } \\
\mathrm{m}\end{array}$ & Medium & High & Medium \\
\hline \multicolumn{2}{|l|}{ Cost } & Low & Low & High & $\begin{array}{l}\text { very } \\
\text { high }\end{array}$ & Expensive & Much Expensive & High \\
\hline
\end{tabular}

\section{NEED OF SEPARATE}

\section{DEVELOPMENT MODEL FOR MOBILE APPLICATIONS}

The characteristics considered for developing all software applications which are called productivity factors such as, Functionality requirements, Reliability requirements, Usability requirements, Efficiency requirements, Maintainability requirements and Portability requirements are common. But there are certain characteristics specific for developing mobile applications in addition to all other productivity factors. Laudson and Gibeon (2014) [5] have done a systematic review to identify characteristics that are inherent to systems and mobile. The 13 types of characteristics have been observed by them .The description of each characteristic identified is given below:-

1. Limited energy: Every mobile device is powered by battery and it has a certain lifetime period, so the applications must be programmed to require the minimal amount of hardware resources possible.

2. Graphical Interface: Due to the reduced screen size, the interface design is limited.

3. Input Interface: How the user will interact with the application?

4. Bandwidth: A mobile application might have the maximum band at times and the minimum in other moments. Some types of applications need to realize this and act differently in each situation.

5. Change of context: The data entries explicitly provided by users and implicit entries concerning the physical and computational context of the users and the environments that surround them are different.

6. Limited Performance: Due to its size and technological advancement all mobile devices, even the most advanced in its class, have limitations of specific resources such as processing power, memory and connectivity. Because of this, the performance is limited.Reduced memory: Due to limited hardware size, less memory is available.

7. Connectivity: Mobile applications can be developed to support different types of connectivity such as $3 \mathrm{G}$, Bluetooth, infrared, Wi-Fi, Wireless, NFC and others.

8. Constant Interruption of Activities: Some applications are developed to work offline and are synchronized when becomes online.

9. Portability: Hardware Portability, a mobile application should be able to run on the largest number of devices possible. Software Portability, a Mobile application should be able to perform same way on all types of operating systems.

10. Response time:The app development should be focused in the time variable. It requires the applications to be developed with a possible resource optimization for a better efficiency and response time.

11. Processing: Response Time is directly related to the power of Processing.

12. Native vs. Web Mobile: It must be defined if the application will be designed to be installed on the device itself, which is known as native applications, or used on the web.

\subsection{Classification of Mobile Applications}

1. Native Apps: These applications are developed for a specific platform and installed on the device.

2. Hybrid Apps: These applications combine elements of both native and Web applications.

3. Web Apps: Web based applications are accessible through the browser on device or third party browsers installed on the device. 


\subsection{Challenges in developing Mobile Applications}

The mobile apps development has different set of problems that are not experienced in the traditional apps development: 1. Fragmentation: Multiple devices in the market with different versions of OS.

2. Testing on multiple devices: As there is large number of mobile devices, it is not feasible to get new device every time and simulators are not reliable.Time to market: Time to market is reduced greatly.Very short and rapid release cycles. 3. Newer Versions: The upgraded version (e.g. typically there is a new Android release every 6-7 months)

4. Multitasking: Because of the small screen size, it is hard to show many applications at same time. With multiple applications open and running in background consumes a lot of battery.

5. Form Factor: There are different form of Mobile devices such as phones and tablets. Developing the apps for different forms is related but designing apps for them is very different.

6. Diversity: The diversity of handsets (e.g. Android-based) in terms of screen size, OEM, operators. Etc.

\section{LITERATURE OF VARIOUS EXISTING SOFTWARE PROCESS MODELS USED FOR MOBILE APPLICATION DEVELOPMENT}

For developing a mobile application, traditional software development methods are applied ignoring characteristics specific to mobile devices such as memory capacity, processing power, graphic interface, connectivity factor, bandwidth factor, lower battery factor, input interface factor, which are different as compared to desktop applications. So, it is required to have a distinct mobile application development lifecycle model. In addition to this, mobile applications are developed fast and thus have faster lifecycle than traditional application and so the lifecycle supervision of mobile app development should be changed that way. The differences in the development of applications in desktop/laptop and in mobile phones with respect to:-
a) Hardware
b) Operating System (OS).
c) Nature and size of the applications
d) Operational environments (where and when the device is used) and usage profiles (how the device is used).
e) Display functionalities

\subsection{Various existing Software Development Life Cycle models adapted to Mobile Application Development Life Cycle are listed below:- \\ 4.1.1Spiral Process Model}

The spiral process model used for mobile development is proposed by Ann Nosseir et al (2012) [6].This process model has several iterations which all result into prototypes and these prototypes are refined in every step.

1st iteration: Identify all users, tasks and context in which application will be used.

2nd iteration:Prioritize the attributes of usability and define a metric to measure each.

3rd iteration:Specify an ideal and acceptable value for each metric. 4th iteration:Upon development of the application, measure the actual value of each metric. Calculate the rating of each attribute.

5th iteration:Calculate an overall usability rating and compare overall rating.

Figure 2 shows the spiral model.

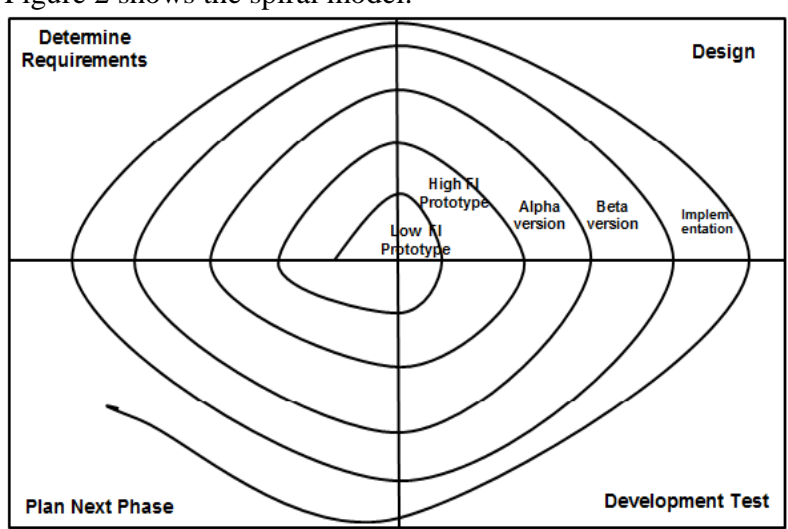

Figure 2:Spiral process model showing Phase 1: Determine Requirements [6]

\subsubsection{Iterative Process Models}

According to Kemper and Wolf (2005) [7],Iterative process model for mobile application development has several separate development sub processes in which the precursor system is revised, bugs are fixed, obsolete features are removed, and new features are included as new modules according to current requirements. Variants of Iterative Process Models: - Incremental models, Evolutionary models, Semi-structured models. Iterative process models are characterized by repeated development blocks and a consequential utilization of prototypical methods.Figure 3 shows the iterative model.

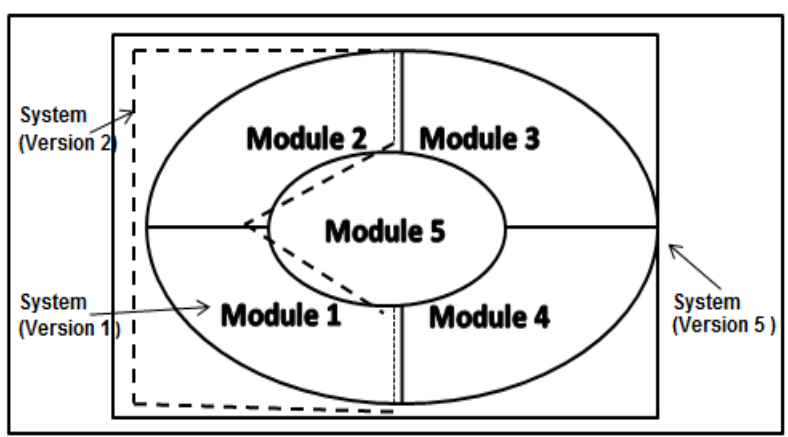

Figure 3: Modular Developments in Iterative Process Models [8]

\subsubsection{Agile Methodologies for development of mobile applications}

Various Agile methodologies have been proposed by different authors. Abrahamsson, et al. (2004) [9] proposed MobileDprocess for developing mobile applications. Mobile D goesthrough five phases:Explore, Initialize, Productionize, Stabilize and System Test \& Fix.Figure 4 shows various Mobile-D phases and stages.Spataru in 2010 [11] proposed the same Mobile $-\mathrm{D}$ with an added phase called Evolve that focus on apps future releases.

Rahimian andRamsin (2008) [12] proposed a methodological approach called Hybrid Methodology Design for mobile 
application development. This approach forms its basis on belief that a single process can not fit in all situations. So it emphasize on creating different development methodologies for different setups. This process for mobile development methodology goes through four iterations Analysis, Design, Implementation, Test, and Transition. For achieving this it combines other agile methodologies, Adaptive Software Development (ASD) and New Product Development (NPD).

Dooms et al. (2005) [13] has proposed 'RaPiD7' (rapid production of documentation, 7 steps) which was developed by nokia in 2000-2001.This method include both documentation and human interaction which are more focused in agile methodologies. For project planning, how much human interaction is needed for decision making is also planned in form of facilitated workshop. RaPiD7 goes through three-layer structure: Project, Case and Workshop layers.

Jeong et al. (2008) [14] proposed the Mobile Application Software Agile Methodology (MASAM) for developing the mobile applications. It includes advantages of SPEM (Software and Systems Process Engineering Meta Model).For rapid development of apps, agile methodology is used and later skeleton code for $\mathrm{s} / \mathrm{w}$ platform is generated. .MASAM goes through four steps: Preparation Phase, Embodiment Phase, Product Developing Phase and Commercialization Phase

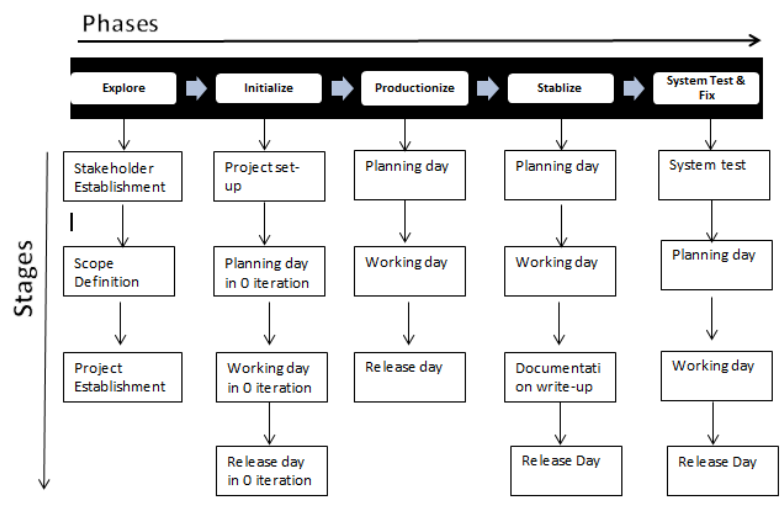

Figure 4: Mobile-D phases and stages [10]

\subsubsection{Mobile Application Development Lifecycle (MADLC)}

TejasVithaniandAnand Kumar (2014) [15] proposed a Mobile Application Development Lifecycle (MADLC) that includes the following phases: Identification, Design, Development, Prototyping, Testing and Maintenance.

1. Identification Phase:-In the first phase, ideas are collected and categorized. The ideas can come from the customer or from the developers.

2. Design Phase:-In this phase, the idea from the mobile application team is developed into an initial design of the application.

3. Development Phase:-In this phase, the application is coded. Coding for different modules of the same prototype can proceed in parallel.

4. Prototyping Phase: -In this phase, the functional requirements of each prototype are analyzed; the prototypes are tested and sent to the client for feedback. After feedback, the required changes are implemented through the development phase. When the second prototype is ready, it is integrated with the first prototype, tested and then sent to the client. The development, prototyping and testing phases are repeated until the final prototype is ready.

5. Testing Phase:-The testing of the prototype types is performed on an emulator/simulator followed by testing on the real device.

6. Deployment Phase: - After the testing is completed and the final feedback is obtained from the client, the application is ready for the deployment.

7. Maintenance Phase: - Feedback is collected from users and required changes are made in the form of bug fixes or improvements. Figure 5 shows Mobile Application Development Lifecycle

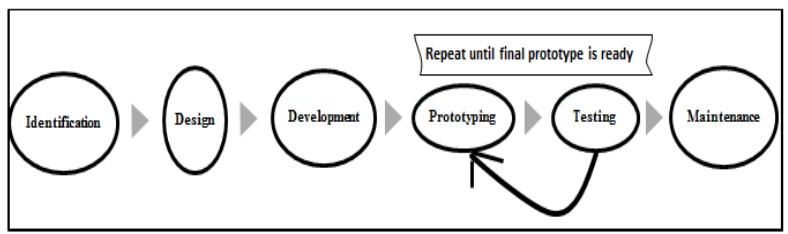

Figure 5: Mobile Application Development Lifecycle (MADLC) [15]

\subsubsection{Model-Driven Mobile Application}

Development

Fernandez and Hussmann (2008) [16] proposed another method for mobile application development.They started creating mobile applications by developing high-level and platform independent model of an application. Then later this high level is converted into platform dependent code. Figure 6 shows the model -driven development.The steps for Mobile Application development are as follows:-

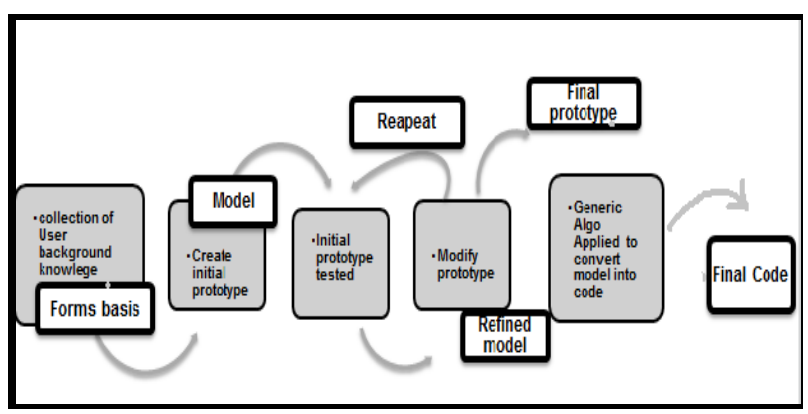

Figure 6: Model-driven Development [16]

\subsection{Comparison of Various Process Model adopted in Mobile application development}

The appropriateness of existing process models adapted to mobile application process models with respect to mobile application development has been assessed on some specific characteristics. Table 2 shows comparison between various process models used in mobile application development. 
Table 2: Comparison of Various Process Model adopted in Mobile application development

\begin{tabular}{|c|c|c|c|c|c|}
\hline $\begin{array}{l}\text { Process Model Applicable } \rightarrow \\
\text { Characteristics of Mobile } \\
\text { Apps } \\
\downarrow\end{array}$ & Spiral model & Iterative model & Agile models & MADLC & Model-Driven \\
\hline Environment & Stable & $\begin{array}{l}\text { High volatile } \\
\text { environment }\end{array}$ & $\begin{array}{l}\text { High volatile } \\
\text { environment }\end{array}$ & $\begin{array}{l}\text { High volatile } \\
\text { environment }\end{array}$ & $\begin{array}{l}\text { High volatile } \\
\text { environment }\end{array}$ \\
\hline Focus & $\begin{array}{l}\text { Risks } \\
\text { involved }\end{array}$ & $\begin{array}{l}\text { The main focus is } \\
\text { on producing new } \\
\text { version of app at } \\
\text { the end of } \\
\text { iteration to satisfy } \\
\text { customer needs. }\end{array}$ & $\begin{array}{l}\text { Human aspects of } \\
\text { software } \\
\text { engineering }\end{array}$ & $\begin{array}{l}\text { The main focus is } \\
\text { on dividing } \\
\text { functional } \\
\text { requirements are } \\
\text { into various } \\
\text { modules and they } \\
\text { are delivered } \\
\text { as prototype at } \\
\text { different } \\
\text { Interims. }\end{array}$ & $\begin{array}{l}\text { User-centered } \\
\text { design }\end{array}$ \\
\hline Team size & Large & Medium & Small team & Small & Small \\
\hline Reliability & Less & High & Less & N/A & Less \\
\hline Application Size & Large & Large & Small & Small & Small \\
\hline Time to market & Long & Short & Short & Short & Short \\
\hline Multiple Platform & N/A & N/A & N/A & Yes & $\begin{array}{l}\text { Reduction in } \\
\text { rewriting code } \\
\text { again and again, } \\
\text { Easy to understand } \\
\text { and Non-experts } \\
\text { can easily create } \\
\text { specialized mobile } \\
\text { applications }\end{array}$ \\
\hline Suitability & $\begin{array}{l}\text { Large, } \\
\text { expensive, } \\
\text { and } \\
\text { complicated } \\
\text { projects }\end{array}$ & $\begin{array}{l}\text { Complex and } \\
\text { dynamic } \\
\text { Applications }\end{array}$ & $\begin{array}{l}\text { For small } \\
\text { organizations, } \\
\text { developmental } \\
\text { and non- } \\
\text { sequential } \\
\text { projects }\end{array}$ & $\begin{array}{l}\text { For apps which } \\
\text { have similar idea } \\
\text { and are already } \\
\text { existing } \\
\text { market. }\end{array}$ & $\begin{array}{l}\text { Non-experts can } \\
\text { easily create } \\
\text { specialized mobile } \\
\text { applications. }\end{array}$ \\
\hline Architecture & $\begin{array}{l}\text { Designed for } \\
\text { current and } \\
\text { foreseeable } \\
\text { requirements }\end{array}$ & $\begin{array}{l}\text { Designed when } \\
\text { requirements of } \\
\text { the complete } \\
\text { system are clearly } \\
\text { defined and } \\
\text { understood. }\end{array}$ & $\begin{array}{l}\text { Designed for } \\
\text { current } \\
\text { requirements }\end{array}$ & $\begin{array}{l}\text { Designed for } \\
\text { users } \\
\text { requirements and } \\
\text { users himself } \\
\text { comes out with } \\
\text { an idea of how to } \\
\text { develop, the idea } \\
\text { is further detailed } \\
\text { and analyzed. }\end{array}$ & $\begin{array}{l}\text { Designed for more } \\
\text { focus on the design } \\
\text { and logic of the } \\
\text { application }\end{array}$ \\
\hline Refactoring & Expensive & Inexpensive & Inexpensive & Inexpensive & Inexpensive \\
\hline Users Involvement & $\begin{array}{l}\text { Throughout } \\
\text { the life cycle }\end{array}$ & $\begin{array}{l}\text { At the end of } \\
\text { every iteration }\end{array}$ & $\begin{array}{l}\text { Constant } \\
\text { feedback from the } \\
\text { user }\end{array}$ & $\begin{array}{l}\text { Constant } \\
\text { feedback from the } \\
\text { user }\end{array}$ & Not much \\
\hline Documentation & Heavy & High & Low & High & Low \\
\hline
\end{tabular}

\section{CONCLUSION}

From the literature review it can be concluded that there is no specific or precise process model for Mobile Application Development. Research scope is concentrated on specific characteristics of the Mobile Apps which are presently not stressed upon and they are not examined in all the existing process models which are adapted in Mobile application development. It also facilitates a thorough insight into each process model and their suitability to a specific app. This analysis will also help mobile apps developers to select appropriate process model for requisite needs. The mobile application developing methodologies discussed in the paper will assist enterprises for planning and developing mobile strategies and applications.Alsoit will help them in understanding the particularities of mobile apps and their shorter development cycle which requires updates more frequently.

In conclusion, this paper helps in providing significant support to practitioners who can be benefited from this analysisfor better comprehend and compare current trends in the mobile application development.

\section{REFERENCES}

[1] http://www.gsgtelco.com/2014/12/19/infographic-thenext-three-years-in-mobile/ (accessed on 23/2/2015) 
[2] http://www.idc.com/getdoc.jsp?containerId=prUS253505 14 (accessed on 23/2/2015)

[3] http://www.forbes.com/sites/briansolomon/2015/01/06/s hopping-apps-are-now-the-fastest-growing-thing-inmobile/(accessed on 23/2/2015)

[4] Intel Research, "Mobile Computing Trends: Insight into Today’s Workforce," Intel IT Center, 2013.

[5] De Souza, Silva L., and de Aquino G.S., (2014), "Mobile Application Development: How to Estimate the Effort?" Computational Science and Its Applications-ICCSA 2014. Springer International Publishing, pp.63-72.

[6] Nosseir, A., Flood, D., Harrison, R., Ibrahim, O. (2012)," Mobile development process spiral" 7th Intl. Conference on Computer Engineering \& Systems, pp. 281-286. 2012.

[7] Kemper, H.-G. and E. Wolf (2005), "Iterative Process Models for Mobile Application Systems: A Framework", Proceedings of the 23rd International Conference on InformationSystem, pp. 401-413

[8] Balzert, H.Lehrbuch der Software-Technik. Software Entwicklung. (2nd Ed.). Heidelberg Berlin, 2000, p. 56

[9] Abrahamsson, P., Hanhineva, A., Hulkko, H., Ihme, T., Jäälinoja, J., Korkala, M., et al. (2004), "Mobile-D: an agile approach for mobile application development." Conference on Object Oriented Programming Systems Languages and Application; Companion to the 19th annual ACM SIGPLAN conference on Object-oriented programming systems, languages, and applications(pp. 174-175). Vancouver: ACM.

[10] Abrahamsson, P., Salo, O., Ronkainen, J., \&Warsta, J. (2002). Agile Software Development Metods: Review and Analysis. VTT Electronics.
[11] A. C. Spataru, Agile Development Methods for Mobile Applications, School of Informatics, University of Edinburgh, 2010, https://www.inf.ed.ac.uk/ publications/thesis/online/ IM100767.pdf

[12] Rahimian V., Ramsin R., "Designing an Agile Methodology for Mobile Software Development: A Hybrid Method Engineering Approach" (2008), Second International Conference on Research Challenges in Information Science, RCIS 2008, pp. 337-342. doi: $10.1109 /$ RCIS.2008.4632123

[13] Ko Dooms, RoopeKylmäkoski, "Comprehensivedocumentation made agile experiments with RaPiD7in Philips", In Proceedings of the 6th InternationalConference on Product Focused Software ProcessImprovement - PROFES 2005, pp 224233. doi:10.1007/11497455_19

[14] Yang-Jae Jeong, Ji-Hyeon Lee, Gyu-Sang Shin (2008), "Development Process of Mobile Application SW Based on Agile Methodology", 10th International Conference on Advanced Communication Technology, ICACT 2008, vol.1, pp. 362-366. doi: 10.1109/ICACT.2008.4493779

[15] TejasVithaniandAnand Kumar(2014) ,"Modeling the Mobile Application Development Lifecycle",Proceedings of the International MultiConference of Engineers and Computer Scientists 2014 Vol I,IMECS 2014, March 12 - 14, Hong Kong

[16] Balagtas-Fernandez, F., \& Hussmann, H. (2008). "Model-Driven Development of Mobile Applications", 23rd IEEE/ACM International Conference on Automated Software Engineering, (pp. 509-512). L'Aquila 